\title{
ENVIRONMENTAL SUSTAINABILITY OPPORTUNITIES AT INFORMAL SETTLEMENTS IN UNESCO WORLD HERITAGE AREAS: A CASE STUDY OF HUE, VIETNAM
}

\author{
BRONTE NIXON \\ WSP Australia Ltd and the University of South Australia, Australia
}

\begin{abstract}
Within a "socialist-state" context; Vietnam is a relatively progressive nation with strong economic and diplomatic growth. But it has not always been this way. Vietnam has a legacy of occupation, division and conflict. The informal settlement at the Hue Citadel; a UNESCO World Heritage site, became established during the Vietnam War in response to displacement and the need for protection. The informal settlement now comprises hundreds of dwellings situated around, and on top of, the Citadel walls. Without sufficient access to clean water, sanitation or waste management; coupled with a lack of infrastructure, the Hue informal settlement has impacted significantly upon the environment. Waterways have high nutrient levels and are stagnant and carp-infested and rubbish and waste is disposed of to waterways and streets. These issues are in-turn impacting upon the integrity of the heritage listing itself. As a result of this; there is now a push by the Thua-Thien-Hue Province to relocate informal settlement residents to new locations outside of the Citadel. This paper discusses the limited success of such relocation programs and alternatively outlines the potential to implement an incremental environmental improvement plan that could contribute to local sustainability and allow residents to remain in an area within which they have strong community connections.

Keywords: hue, informal settlements, world heritage, sustainability, environmental impacts.
\end{abstract}

\section{INTRODUCTION}

Vietnam is a rapidly urbanising country that retains strong links to its cultural identity and history. Years of invasion and conflict have tested these links but Vietnam has emerged in the 21 st century as a progressive country with a growing economy and significant tourism potential. Despite these advances though, Vietnam remains, at heart, a developing country facing complex environmental challenges. Think of Vietnam and one cannot help but visualise the multitude of images documenting the American War in Vietnam. For many; the war is a continuing symbol of the country's internal and external struggles, resulting in social and environmental impacts that will take generations to heal. As a rapidly growing economy, increased growth in Vietnam is placing significant pressure on the natural environment and existing infrastructure [1]. The situation in Hue in the Thua-Thien-Hue province though, is slightly different. Hue Citadel has been home to informal settlements since the 1940's with the issue being significantly exacerbated during the American War in Vietnam when people sought the safety of the Citadel walls. Historically, this did not present a major issue. The situation changed though when the site was given UNESCO (United Nations Educational, Scientific and Cultural Organisation) World Heritage status in 1993. Suddenly families who had lived at the site for generations were no longer welcome.

Unfortunately, a UNESCO World Heritage listing, whilst having significant economic value to a region or country through tourism generation, often has a detrimental effect on those communities that are already living within or around the site. The natural environment of the Hue Citadel is heavily degraded, waterways have high nutrient levels and are stagnant and carp-infested, rubbish and waste is disposed of directly to waterways and streets, and 
informal horticultural practices are impacting upon soil and water quality. In response to these issues the Thua-Thien-Hue Province is now relocating informal settlement residents to new locations outside of the Citadel.

\section{HUE CITADEL - CONTEXT}

\subsection{Hue Citadel and the UNESCO world heritage listing}

Vietnam stretches for 1,650 kilometres from north to south along the Indochina Peninsula. The capital of Vietnam is Hanoi; situated in the north of the country. Ho Chi Minh City is the largest city in Vietnam and is in the south of the country. Hue has a population of about 340,000 people and is situated within the Thua Thien Hue Province in central Vietnam approximately 540 kilometres south of Hanoi [2]. Hue Citadel is located on the banks of the Perfume River and is home to 60,000 residents [3]. Hue Citadel was the imperial capital of the Nguyen Dynasty (1802-1945) [4]. The citadel became a key religious and cultural centre during the dynasty's 143-year reign [2]. Due to its cultural significance, Hue Citadel was given World Heritage status by UNESCO in 1993 [4], [5]. The site contains extensive examples of intangible cultural heritage, unique architecture, historical monuments, gardens and landscape features [2] (Fig. 1(a) and (b)). The 232 Ha site is managed by the Hue Monuments Conservation Centre and receives millions of visitors every year [5]. The structures and features of the Citadel, including the heritage walls, now require extensive maintenance and restoration.

\subsection{Hue and the American War in Vietnam}

Hue was the location of one of the bloodiest battles of the American War in Vietnam during the 1968 Tet Offensive [6]. Hue was located 75 kilometres south of the demilitarised zone during the war and was captured by the People's Army of Vietnam and the Viet Cong. Thousands of people were killed during the battle to retake the city by US Marines and South Vietnamese Troops. Much of the city was destroyed during the Tet Offensive - including the Imperial Citadel (Fig. 2(a) and (b)). It was also during this battle that many civilians escaped into the Citadel seeking protection by establishing temporary accommodation.

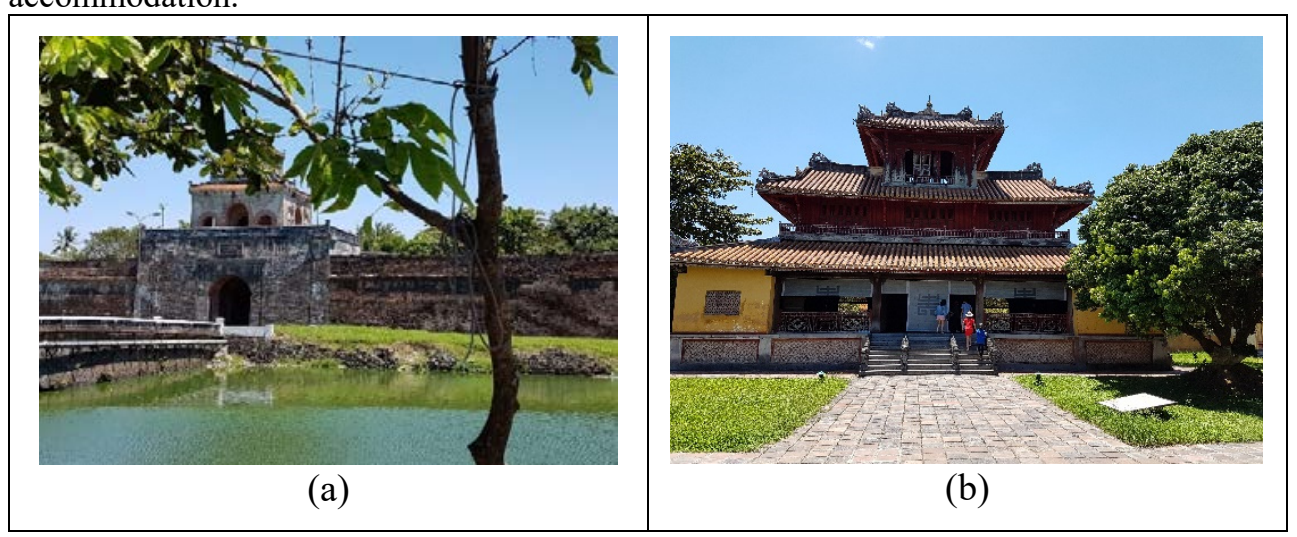

Figure 1: Hue Citadel. 


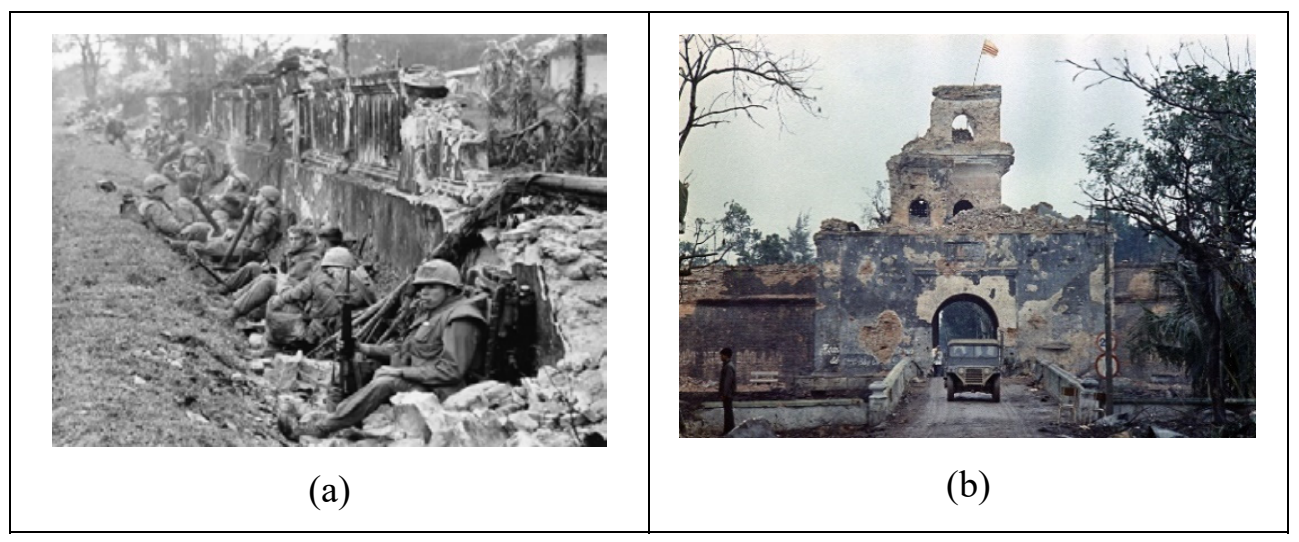

Figure 2: Hue Citadel during the American War in Vietnam [7].

\section{INFORMAL SETTLEMENTS}

\subsection{Background}

At its most simplistic, housing can be divided into two categories - formal and informal [8]. The UN-HABITAT estimates that worldwide; more one billion people live in informal settlements [9]. Informal settlements are generally always poorly serviced, lacking in essential infrastructure, situated on illegally occupied land and in non-compliance with building regulations [10]. Common themes of informal settlements include: inadequate sanitation systems, inadequate access to clean water, poor structural quality of housing, overcrowding, environmental degradation, lack of social investment and infrastructure, insecure tenure and illegal subdivision [9]. Many Vietnamese informal settlements occur because the transition from State-housing to privatised housing resulted in inequitable access to improved housing stock [11]. In Hue, however, the war was instrumental in the growth of the informal settlement. As with other informal settlements, the houses have no formal legal tenure, there is a lack of infrastructure, the housing is of poor quality and there is overcrowding. There is, however, a real desire to stay in the current location. Without any town planning, informal settlements generally have no provision for infrastructure, let alone consideration of the natural environment [12]. With these areas lacking in essential services it often falls to waterways to fulfil that duty. This is the case with the Hue informal settlement; with the Perfume River taking on the role of water supply and waste disposal.

\subsection{Environmental issues at informal settlements}

The environmental impacts associated with informal settlements are often an exacerbation of the environmental issues facing developing countries. In Vietnam; environmental issues can be generalised into; site contamination, water pollution, groundwater contamination, overexploitation of natural resources, salinisation of waterways and air pollution [13]. These issues; generally experienced across much of Vietnam, are coupled with the specific environmental and social challenges that characterise all informal settlements resulting from both the unplanned use of marginal land, high urban densities and lack of infrastructure. The 
following section provides a brief overview of the general environmental challenges faced by informal settlements around the world.

Rapid urbanisation and migration by the poor in search of work - Informal settlements are characterised by their rapid growth and settlement by the poor for whom proximity to work opportunities over-rides the physical hazards of settling on marginal land [11]. In a 2012 study, it was found that the population of Xalapa City in Veracruz, Mexico increased by more than $300 \%$ between the 1960 s and 1980 to more than 200,000 . It then doubled again from 1980 as people migrated from rural areas in search of work. The resulting impacts were catastrophic with $90 \%$ of the land being irrevocably altered [12].

The dual role of waterways as both sewage disposal system and potable water supply - With informal settlements generally having either no or inadequate sanitation systems, waste and wastewater drainage infrastructure or any fresh water supply; it often falls upon the closest river to fulfil that role. In many areas, a single waterway will comprise the local sewage system - and also be the only source of drinking water [14]. In the Kambi Moto informal settlement on the outskirts of Nairobi there is a lack of freshwater even though a river runs through the settlement [15]. The river is so polluted through its use as a sewage system that the water cannot be used for any other purpose.

Rubbish disposal and the lack of waste management services - Lack of a formalised waste management system is characteristic of most informal settlements. Rubbish and general waste is therefore discarded to waterways and roadsides. Any runoff interceded by areas where waste has been dumped becomes nutrient laden - adding to existing water quality problems in waterways. In a study on informal settlements in Lagos, Nigeria it was found that so much solid waste was being generated that government authorities did not have the capacity to address the issue alone [16]. The private sector was therefore engaged, however inappropriate roads and infrastructure and a lack of community education means that waste continues to pile up in streets and waterways.

The implications of erosion, run-off and drainage in unsealed settlements - In marginal areas settled by poorer people; the quality of street paving or formal civil drainage systems is hardly going to be a priority. In many European informal settlements, however, it was found that rubbish is disposed of in the streets with subsequent leachate entering waterways. Rapid construction using substandard materials in the absence of development regulations is also resulting in sedimentation and run-off entering waterways [17].

\subsection{The dichotomy of world heritage for informal settlements}

World Heritage status represents the pinnacle of international efforts to conserve the most significant heritage sites in the world [18]. A World Heritage listing, however, can be a double-edged sword. On the one hand; the listing will inevitably attract tourists and investment. On the other hand, it comes with exclusions for local people; resulting in dispossession of land and loss of income. This can exclude people from an area to which they have strong social and cultural capital. Displacement caused by World Heritage conservation is unsustainable and anti-ethical to cultural heritage conservation aims [19]. Residents of the Hue informal settlement are progressively being resettled; but what impact will this have on the cultural heritage that they leave behind? Devoid of community life; would Hue Citadel be more or less attractive to tourists? 


\subsection{Informal settlements and relocation programs}

Resettlement programs have become an integral part of many urban projects in Vietnam [11]. These are generally a result of the construction of new infrastructure and urban regeneration.

It is estimated that around the world; 15 million people are displaced every year by development projects [20]. Increasingly, this includes people who are forced to move for conservation purposes. A common response to the declaration of a World Heritage Place has been the forced eviction of existing, local communities. Yet these resettlement programs can have detrimental effects on the livelihood, social cohesion, mental health and wellbeing of displaced populations [21].

A recent study from Cambodia found that the distance of resettlement sites from the original locality directly correlated with the degree of adversity that people experienced. Most resettled people in the Cambodian study were later found to be in debt and had to travel extensive distances to work at the old location; only returning at night or on the weekends [20]. Likewise, in Suwan Prasit 2; a resettlement project in Bangkok; a study involved interviewing a community immediately after resettlement and then again twenty years later. It was found that few of the original inhabitants had remained - with many being replaced by newer residents with higher incomes [22]. In a study investigating the effects of the forced relocation of the Wells Estate community in South Africa, residents felt that they had more control over their lives at their previous location. Post-relocation; schools and employment were further away and many residents became unemployed [23]. In two examples of World Heritage designations in China (Yinhuwan Village at Mount Sanqingshan and the Ancient City of Ping Yao in Shanxi Province) heritage tourism became the major focus of the government and local communities were moved off their lands. Access restrictions were then enforced through ticketing for admission and residents could no longer afford to visit their own city [24], [25].

\subsection{Environmental improvements at informal settlements}

An alternative to community resettlement is environmental improvement within a sustainability context. Approaches to community environmental improvement differ in theory but the desired outcomes are the same - local, on-ground changes leading to broader long-term sustainability. This can be achieved through participation in upgrading initiatives, behaviour change programs and local economic development opportunities. Community participation is integral to any environmental improvement plan and the process must be collaborative - informal settlement communities cannot have decisions made for them; social and environmental benefits must be understood and actions developed together. In a World Heritage context; it is only through collaborative and integrated solutions that any improvements can be made. Such approaches have been shown to work well in the past. For example, the informal settlement community of Kambi Moto in Nairobi formed an advocacy group in 2000 to negotiate with the government. With the help of an international development agency a community savings scheme was established, infrastructure improvements were initiated, houses were improved and properties were given water taps, toilets, sewer connections, electricity and waste services [15]. There is still a long way to go in Kambi Moto, but this example demonstrates what can be achieved through communitydriven initiatives and government support. 


\section{HUE CITADEL ENVIRONMENTAL STUDY}

\subsection{Methodology}

The approach to the Hue Citadel environmental study comprised the following three stages:

1. Environmental observations - Observations of the project area were made during a study trip to the site in June 2017. Observations were made over a two-week period. The quality of housing and infrastructure were noted; environmental behaviours were observed and environmental conditions were assessed.

2. Consolidation of literature - To understand the conflicting issues in the area a thorough literature review was undertaken focussing on the Hue Citadel, informal settlements, world heritage and environmental improvement opportunities.

3. Community surveys - To gain an understanding of environmental behaviours a community survey was prepared. The survey was designed to be simple and easy to interpret. Twenty-two (22) informal settlement households participated.

\subsection{Findings - environmental observations and environmental information}

Water quality - Visual inspections of the Citadel noted signs of eutrophication in the waterways indicating high nutrient levels. High levels of single species macro-phytic growth in some lakes - and absolutely no aquatic vegetation growth in other lakes demonstrates the generally unhealthy state of the waterways. Waterways were obviously stagnant with low turbidity and probable low dissolved oxygen levels. Algal blooms were noted to reform relatively quickly after rain events. Species of Cyprinidae family (carp) were observed in many of the waterways. Carp are generally found in still or slowly flowing waters, can exist in areas with extensive macrophytic growth, can tolerate a range of environmental conditions, have a high tolerance of low oxygen levels, pollutants and turbidity and adapt well to degraded areas. Faecal coliform levels in four of the Citadel lakes; TinhTam, CayMung, TanMieu and HoVe have been previously studied [3]. All lakes returned high faecal coliform contamination levels (between $780 \mathrm{MPN} / 100$ and 4,050 MPN/100 mL). In addition to faecal coliforms; E. coli (Escherichia coli) and COD (chemical oxygen demand) measurements were also found to exceed regulations [14]. Phosphorus levels were found to be very high in the Citadel (41.2 kg P/ha year) with untreated sewage the largest source of phosphorus loading [26]. Extremely high nitrogen levels have also been recorded. Domestic wastewater is not collected or treated anywhere in the city of Hue [5]. Wastewater flows directly into the Perfume River and the lakes and canal of the Citadel.

Flooding, inundation and siltation - Canals and waterways were observed to be excessively silted with subsequent low or absent water flows. There is limited drainage capacity which would contribute to inundation during rainfall events. The physical characteristics of the lakes and canal system have changed over recent years due to rapid urbanisation with the surface area of the lakes decreasing. As an example; from 2003 to 2007 the total area of the lakes decreased by $18 \%$ [27]. Large-scale floods used to occur in Hue approximately every 50 years, however since 1993 they have been occurring every three years [4]. This is a result of climate change impacts and excessive deforestation upstream of the Perfume River. Siltation and sedimentation in the waterways is primarily a result of construction without sediment or drainage control measures, construction within the floodplain, current low flows of water, sewage and waste accumulation and the lack of 
appropriate infrastructure. Lakes are also being used for the farming of water spinach (rau muống); further impeding flows.

Waste management - Rubbish could be seen discarded in piles along the streets and in waterways (Fig. 3(a)). Levels of discarded rubbish is significant; particularly in the canal and some of the lakes. Organic waste is in varying states of decomposition in the waterways and is contributing to significant eutrophication issues. Limited sole-operator plastic bottle and tin can recycling occurs. Ninety-five percent of rubbish in the City of Hue is collected, transported and disposed of to landfill [5]. There is no regular collection at the informal settlements of the Hue Citadel. There is no separate hazardous waste disposal site - all waste is disposed of to the same facility.

Air quality - Several issues were observed that could contribute to a reduction in the air quality in the Citadel. This included unsealed roads, open fires, rubbish incineration, construction activities, unprotected stockpiles and traffic. The concentration of suspended particulates, sulfur dioxide, carbon dioxide and manonitrogen oxides is high in industrial areas and along roadsides [5].

Informal land uses - Observed land practices included informal agricultural practices both on the Citadel walls and within the silted-up waterways. Vegetables (including rau muống water spinach), herbs and spices, fruit and grain is all grown within the heritagelisted walls. Chickens, pigs and aquaculture were all observed. Animal feed and waste and fertilisers are all assumed to be contributing to water quality issues via run-off.

Informal settlement relocation plan - Farms and dwellings on the Citadel walls are destined for demolition as these properties are considered illegal by Hue authorities Fig. 3(b)). Some sections having been already cleared. Remaining residents will be moved from the Hue informal settlement to two relocation sites away from the local area. The Thus-ThienHue provincial government has been actively promoting the relocation of these people under a resettlement policy since 1992. All land from which people have been removed is intended to be converted to public use [4], however it has been observed that as people are relocated and dwellings are cleared; new residents occasionally take their place [19]. The relocation of these households has proven to be challenging as people have strong, pre-established social and economic links to the Citadel.

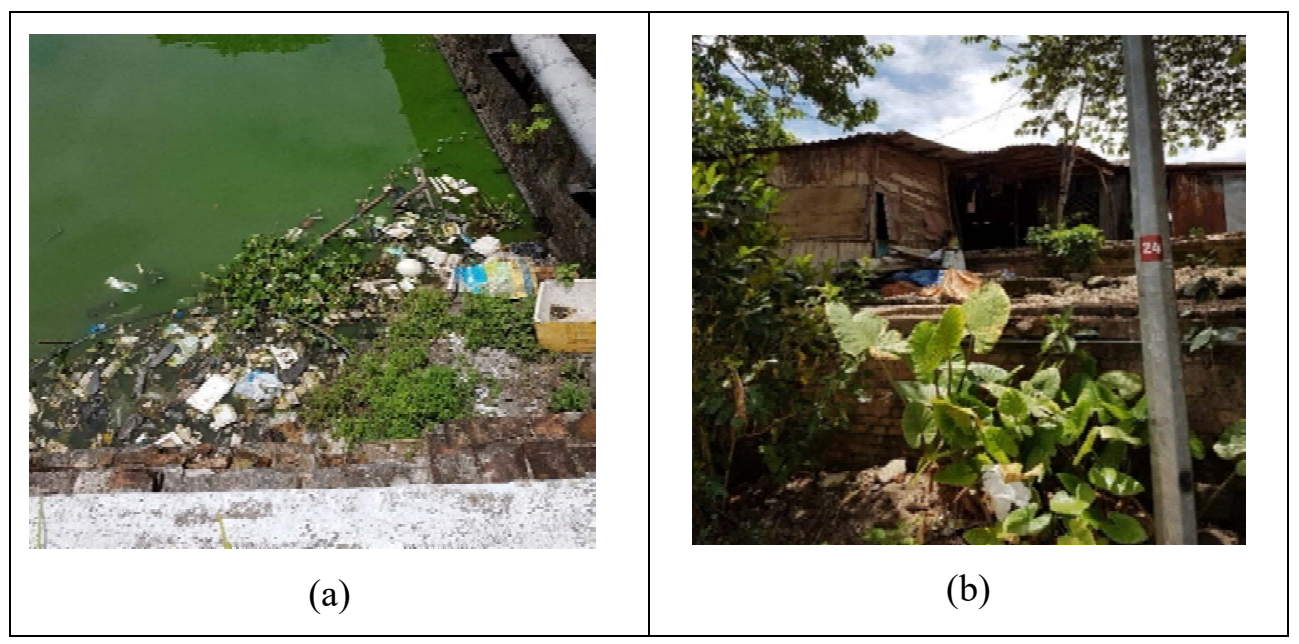

Figure 3: Hue Citadel informal settlement - environmental issues. 


\subsection{Findings - community surveys}

Twenty-seven questions were presented to survey participants, this included questions to gain background demographic data, employment information, access to essential services and infrastructure, environmental values, environmental behaviours, land use information and housing. As outlined earlier, 22 household were surveyed; half of those were in the southeastern section of the Citadel and half were in the north-western section.

Over half of all respondents interviewed were over 50 years of age. Average household occupancy levels were between 5.3 and 6.1 in the south-east. Average house occupancy levels in the North-West were 4.9. The South-East sector was found to be more densely populated. Thirty three percent $(33 \%)$ of respondents in the South-East sector had experienced flood damage at some point and $90 \%$ of North-West residents had experienced flood damage. Nearly $60 \%$ of respondents had jobs of which over half were in the Citadel. The north-west sector of the informal settlement contained more permanent dwellings $-90 \%$ of observed dwellings were permanent structures. The south-east contained more informal and temporary structures - with only $58 \%$ of observed structures appearing permanent. Most respondents in the north-west wanted to stay in their homes - they had made many home improvements and had invested more in their properties - even though they had no legal tenure. They did not want to relocate. The desire to stay was not as strong in the south-east; particularly for families living in poor quality, temporary structures without any home improvements. Access to clean drinking water was rated as being very important for more than $90 \%$ of respondents - although $27 \%$ currently had no access to drinking water. Likewise, rubbish disposal and the provision of bins was very important for all respondents although current facilities were grossly inadequate. It was found through discussions with respondents that rubbish bins were mostly provided on the streets at a rate of about one single bin every 100 metres. However, in the Hue informal settlement; 100 metres equates to more than 20 households. Rubbish was therefore disposed of in the street and either directly or indirectly into waterways; out of necessity. All respondents said that they would greatly value a formal garbage collection program. Every family said that they would love to have a cleaner and healthier environment and to be given help to achieve this. All families said that they would be willing to learn to improve their local environment, particularly if it meant that they could remain in their current location.

\subsection{Environmental opportunities - integrated environmental planning}

A more sustainable approach to world heritage conservation is needed - one that would assess the value of the Hue Citadel not only from an historical or heritage viewpoint; but from a diverse perspective; considering the Citadel's modern cultural values as well as its historical ones [1]. This is particularly relevant as section 119 of the Operational Guidelines for the Implementation of the World Heritage Convention state that: "World Heritage properties may support a variety of ongoing and proposed uses that are ecologically and culturally sustainable and which may contribute to the quality of life for the communities concerned" [28]. In addition to this, the Management Plan for the Complex of Hue Monuments 20152020 and vision 2030 outlines on page 105 that: "Most of the environmental impacts originate from the everyday lives of the people living on the walls", and; "Provincial government has tried to implement various initiatives, but they need to focus on motivating local people to change their perceptions about waste and their behaviour" [29].

During the literature review undertaken for this paper, several sources were identified that list the various infrastructure proposals and projects currently either being planned or 
constructed in Hue; that directly affect the Citadel [2], [4], [5], [14], [26], [27]. Examples include:

- The construction of a wastewater treatment plant, pump stations and pipelines.

- $\quad$ River, moat, canal and lake dredging and rehabilitation projects

- Bank stability, drainage and pavement works

- Restoration works to the water channels, flood gates and original roadways

- Development of additional landfill facilities

These projects are appropriate and justified in the context of what needs to be achieved for Hue authorities to address the city's environmental problems. They are; however, all being undertaken with disregard to the Hue informal settlement; under the assumption that the community must be relocated. An alternative approach is one that would investigate the possibility of the community staying in their present location with the support of environmental improvements set within a local sustainability context. The only way that these improvements could be made would be through the preparation of an Environmental Improvement Plan that has been prepared in alignment with the UNESCO World Heritage values, the Management Plan of the Complex of Hue Monuments, the Hue Green City Action Plan, Thua-Thien-Hue Province strategic plans, environmental and development planning legislation, research into other environmental action plans for informal settlements around the world and recognition that heritage protection cannot be undertaken in isolation; that the needs of existing communities should always be considered and valued.

\subsection{Environmental opportunities - developing a broad environmental improvement plan}

Taking learnings from the outdated Agenda 21, Local Environmental Action Planning, current Sustainability Planning and Hue Green City policy; a broad approach could be recommended to develop a Pilot Environmental Improvement Plan for the Hue Citadel informal settlement. This process would empower the community to make better environmental choices, aid the community to make decisions about what aspects of the environment are important to them, provide the community with necessary essential services and help the community to become better educated and informed about the heritage implications of their environmental practices. A successful Environmental Improvement Plan for the Hue Informal Settlement would:

- Set an Environmental Vision for the settlement.

- Undertake a thorough assessment and analysis of all proposed and existing infrastructure improvement projects in Hue and investigate how they could be expanded to include the informal settlement.

- Assess all other environmental plans that affect Hue Citadel and try to align aims.

- Set environmental objectives to identify and prioritise environmental challenges, to include all stakeholders in developing the environmental plan, to increase awareness and educate and train the community in improved environmental practices.

- Include comprehensive socio-economic surveys to try and understand sources of social, financial and cultural capital.

- Identify environmental issues through observations, data and survey information and rank issues according to potential heritage impact and community values.

- Develop prioritised actions for each issue and list tasks and activities. It is essential that this would be done in partnership with the local community. 
- Outline implementation procedures and timeframes.

- Identify possible funding sources.

- Monitor success through the development of appropriate indicators and provide a reporting and continuous improvement framework.

Aside from the necessary infrastructure improvements which may be able to be extended to the Citadel, it is recommended that the Environmental Improvement Plan for the Hue Citadel Informal Settlement include the following goals as a minimum:

1. To improve waste management practices

2. To improve rates of waste recovery and recycling

3. To reduce hazardous waste disposal in waterways and public places

4. To improve the water quality of the lakes and canals

5. To provide a clean water supply

6. To improve local air quality conditions

7. To improve soil quality in the catchment area of the lakes and canals

8. To secure and conserve agricultural land

9. To rehabilitate the lakes and canals

10. To educate the community in improving local environmental practices.

For every prioritised goal in the Environmental Improvement Plan, there would be associated actions, tasks, timing, benefits, funding opportunities and environmental indicators developed. Individual tasks would delineate those on-ground activities that can be readily achieved with the right funding and timing. Following the site observations and community surveys undertaken for this project in June 2017, a draft Environmental Improvement Plan was developed based upon the above goals. In all, more than 23 actions and 70 tasks were developed as part of the plan. Sixty key indicators were also developed which could be used to monitor the success of the plan. Any plan developed would need to be done in partnership with the residents of the Hue informal settlement. It would need to be simple, easily accessible and achievable. It would need to be a community plan - owned by them and prepared in conjunction with infrastructure upgrades and environmental education and awareness initiatives.

\section{CONCLUSIONS}

The Informal Settlement at Hue Citadel, which grew rapidly during the American War in Vietnam, is resulting in environmental degradation caused through a lack of appropriate infrastructure and services. This did not pose a significant issue until the site was granted World Heritage status in 1993. Despite this designation, local people want to remain living in the Citadel where they have strong social and economic ties. A more sustainable and equitable approach to World Heritage conservation is therefore recommended here - one that considers both the modern and historical values of the Citadel. A proposed alternative to the government's relocation policy is the development of an environmental improvement plan within a sustainability framework. The plan would require the support of local authorities and need to be integrated with existing infrastructure improvement projects. The implementation of a pilot environmental improvement plan is initially recommended in this paper. Coupled with an appropriate community education and awareness program and the development of robust environmental indicators and reporting frameworks; the potential success of such a plan could then be applied to the wider informal settlement. This may allow the community to minimise their environmental impacts and remain in the Citadel. 


\section{ACKNOWLEDGEMENTS}

The author would like to thank Khanh Tran, Ramin Moradi, Ben Andary, Dr Matthew Rofe, the University of South Australia and the Hue University of Sciences, Vietnam.

\section{REFERENCES}

[1] Clausen, A., Hoa Vu, H. \& Pedrono, M., An evaluation of the environmental impact assessment system in Vietnam: the gap between theory and practice. Environmental Impact Assessment Review, 31, pp. 136-143, 2011.

[2] Santikul, W. et al., Impacts of tourism on the quality of life of local residents in Hue, Vietnam. Anatolia, 27(4), pp. 405-420, 2016.

[3] Kawahara, S. Furukawa, N. \& Satoh, S., Study on methods of conservation and regeneration in the historical water system in a Shanshui City - case study of old town planning in Hue, Vietnam. Proceedings of the 10th Asian Planning Schools Association Conference, Ahmedanad, India, 2009, pp. 1-12, 2009.

[4] Ky, N.M. \& Lam, N.H., Analysis of changing trend of faecal coliform levels at lakes in Hue Citadel, Vietnam. Environment and Natural Resources, 14(1), pp. 1-7, 2016.

[5] ADB., Hue Green City Action Plan, Asian Development Bank: Philippines, 2015.

[6] Willbanks, J., The Tet Offensive: A Concise History, Columbia University Press, 2007.

[7] Peter Alan Lloyd photography. http://peteralanlloyd.com/. Accessed on: 19 Feb. 2018.

[8] Ahmed, I., Sager, J. \& Cuong, L.V., Sustainable low-income urban housing in Vietnam: context and strategies. Open House International, 35(3), pp. 56-65, 2010.

[9] Jiusto, S., Squatting: Developing World. International Encyclopaedia of Housing and Home, Elsevier Ltd: London, 2012.

[10] Okurut, K., Kulabako, R.N., Chenowith, J. \& Charles, K., Assessing demand for improved sustainable sanitation in low-income informal settlements of urban areas. International Journal of Environmental Health Research, 25(1), pp. 81-95, 2015.

[11] Hryczyszyn, K. \& Neil, D., Overwater stilt housing in Can Tho, Vietnam: distribution patterns and implications for development policy and master planning. IDPR, 36(4), pp. 475-502, 2014.

[12] Benitez, G., Perez-Vazquez, A., Nava-Tablada, M., Equihua, M. \& Alvarez-Palacios, J.L., Urban expansion and the environmental effects of informal settlements on the outskirts of Xalapa City, Veracruz, Mexico. Environment and Urbanisation, 24(1), pp. 149-166, 2012.

[13] Nguyen, T.T., Vietnam and the environment: problems and solutions. International Journal of Environmental Studies, 66(1), pp. 1-8, 2009.

[14] Nagano, Y., Teraguchi, T., Lieu, P.K. \& Furumai, H., Characterisation of water pollution in drainage networks using continuous monitoring data in the Citadel area of Hue City, Vietnam. Water Science and Technology, 70(4), pp. 612-619, 2014.

[15] Toomey, B., Slums of hope: land tenure reforms, local economic development and environmental improvement in a Kenyan shanty town. Local Economy, 25(3), pp. 234 239, 2010.

[16] Opoko, A. \& Oluwatayo, A., Private sector participation in domestic waste management in informal settlements in Lagos, Nigeria. Waste Management and Research, 34(12), pp. 1217-1223, 2016.

[17] Badyina, A., Potsiou, C. \& Tsenkova, S., Self-Made Cities: In Search of Sustainable Solutions for Informal Settlements in the United Nations Economic Commission for Europe Region, United Nations Publications, 2009. 
[18] Okech, R., Socio-cultural impacts of tourism on world heritage sites: communities perspectives of Lamu (Kenya) and Zanzibar Islands. Asia Pacific Journal of Tourism Research, 15(3), pp. 339-351, 2010.

[19] Wood, K C., Displacement for conservation: one of the adverse impacts of cultural world heritage management in Hue, Vietnam. Heritage, Chapter 2: Heritage and Society, eds R. Amoeda, S. Lira \& C. Pinheiro, pp. 365-375, 2012.

[20] Connell, J. \& Connell, J., Development-induced displacement, adaptation and mobility in Cambodia. Migration and Development, 5(3), pp. 413-430, 2016.

[21] Brockington, D. \& Igoe, J., Eviction for conservation: a global overview. Conservation and Society, 4(3), pp. 424-470, 2006.

[22] Leeruttanawisut, K. \& Yap, K.S., Suwan Prasit 2: A resettlement project in Bangkok revisited. Community Development Journal, 5(2), pp. 248-267, 2016.

[23] DeMoss-Norman, T., From informal settlements to formality: a resettlement group's adaptation to a newly planned community in Port Elizabeth, South Africa. Economic Anthropology, 2015 2, pp. 224-240, 2015.

[24] Wang, S.Y., From a living city to a world heritage city: authorised heritage conservation and development and its impact on the local community. International Development Planning Review, 34(1), pp. 1-17, 2012.

[25] Su, M.M., Wall, G. \& Xu, K., Heritage tourism and livelihood sustainability of a resettled rural community: Mount Sanqingshan World Heritage Site, China. Journal of Sustainable Tourism, 24(5), pp. 735-757, 2016.

[26] Anh, T.N.Q., Harada, H., Fujii, S., Anh, P.N., Lieu, P.K. \& Tanaka, S., Preliminary analysis of phosphorus flow in Hue Citadel. Water Science and Technology, 17(1), 2016.

[27] Lieu, P.K., Giang, N.B. \& Loc, D.T.T., Current atatus of physical and qastewaterreceiving characteristics of lakes and canal outside Hue Citadel. Sustainable Urban Regeneration, 8 Mar., pp. 18-20, 2011.

[28] UNESCO, Operational Guidelines for the Implementation of the World Heritage Convention, UNESCO, World Heritage Centre, 2017.

[29] HMCC, Management Plan for the Complex of Hue Monuments for the Period 20152020 and Vision 2030, Hue Monuments Conservation Centre and UNESCO, 2015. 